EPJ Web of Conferences 98, 04007 (2015)

DOI: $10.1051 /$ epjconf/ 20159804007

(C) Owned by the authors, published by EDP Sciences - SIF, 2015

\title{
Could the extensive use of rare elements in renewable energy technologies become a cause for concern?
}

\author{
A. M. BradshaW \\ Max-Planck-Institut für Plasmaphysik - Boltzmannstr. 2, 85748 Garching, Germany and \\ Fritz-Haber-Institut der Max-Planck-Gesellschaft - Faradayweg 4-6, 14195 Berlin, Germany \\ B. REuTER \\ Lehrstuhl für Fahrzeugtechnik, Technische Universität München \\ Boltzmannstraße 15, 85748 Garching, Germany \\ T. HAMACHER \\ Institut für Energiewirtschaft und Anwendungstechnik, Technische Universität München \\ Arcisstraße 21, 80333 München, Germany
}

\begin{abstract}
Summary. - The energy transformation process beginning to take place in many countries as a response to climate change will reduce substantially the consumption of fossil fuels, but at the same time cause a large increase in the demand for other raw materials. Whereas it is difficult to estimate the quantities of, for example, iron, copper and aluminium required, the situation is somewhat simpler for the rare elements that might be needed in a sustainable energy economy based largely on photovoltaic sources, wind and possibly nuclear fusion. We consider briefly each of these technologies and discuss the supply risks associated with the rare elements required, if they were to be used in the quantities that might be required for a global energy transformation process. In passing, we point out the need in resource studies to define the terms "rare", "scarce" and "critical" and to use them in a consistent way.
\end{abstract}

This is an Open Access article distributed under the terms of the Creative Commons Attribution License 4.0, which permits unrestricted use, distribution, and reproduction in any medium, provided the original work is properly cited. 


\section{EPJ Web of Conferences}

\section{1. - Introduction}

The transformation of the present energy supply system into one based largely on "renewable", or perhaps better, "sustainable" sources is widely regarded as one of the global challenges of the 21st century. The German Energiewende has attracted considerable attention internationally and is regarded as being in the vanguard of this development: so far, no other major industrial country has made a commitment of such magnitude. In 2010 the Federal Government adopted ambitious new targets for greenhouse gas emission reductions, energy savings and the accelerated construction of renewable energy facilities. A commitment was made to an $18 \%$ share of renewables in the total primary energy market by 2020, in compliance with the EU 20-20-20 policy. Moreover, the Government committed itself to a $60 \%$ contribution by 2050 . Nuclear energy was foreseen only to play the role of a "bridging technology" in order to ease the transition. Shortly afterwards, in 2011, however, the Government - acting in the aftermath of the Fukushima disaster was forced by the weight of public opinion to shut down immediately 8 nuclear reactors and to commit itself to closing the remaining 9 by 2022. This move was accompanied by further legislation, known at the time as the "energy package", to accelerate the extensions to the electricity grid, to promote energy efficiency and to reform the feed-in tariff system. The term Energiewende is now usually taken to mean all the measures in the areas of power generation, heating and transport - including those taken by previous governments prior to 2010 - in order to create sometime later in this century a low-carbon economy in Germany.

Although this process will produce dramatic reductions in the use of fossil fuels, and thus in $\mathrm{CO}_{2}$ emissions, it will require huge amounts of non-fuel raw materials. Vidal et al. [1] estimate that, for equivalent installed capacity, solar and wind facilities require at least an order of magnitude more concrete, glass, iron, copper and aluminium than fossil fuel or nuclear energy power plants. The global energy transformation could therefore lead to a substantial increase in demand for these materials. A conservative estimate for the amount of copper required for this purpose ("in-use stock") by 2050 is 50 million tons [1], corresponding to roughly three times current annual production. (We note that other sources [2] suggest a somewhat lower figure.) Even without such developments recent trends in the consumption of raw materials have been dramatic: the average annual growth rate for the extraction of industrially important metals has been almost 10\% in the last ten years, as fig. 1a — based on data from the United States Geological Survey (USGS) [3] — shows. We also note from this plot that metal extraction increased by a factor of 27 from 1905 to 2012. It can be compared with an increase in world population by a factor of over four during the same period [4,5], showing that the increase per capita is at least a factor of six! Figure $1 \mathrm{~b}$ shows a comparison of the metal extraction rate (actually the same curve as in fig. 1a) with global GDP, given in "1990 International Dollar" using the "Maddison" data [6], in about the same period. Unsurprisingly, metal extraction has grown at approximately the same rate as GDP in the hundred years up to 2008. ("Maddison" GDP data for later years are not, or not yet, available in the currency unit used.) 
LNES 2014

a)

metal extraction and population

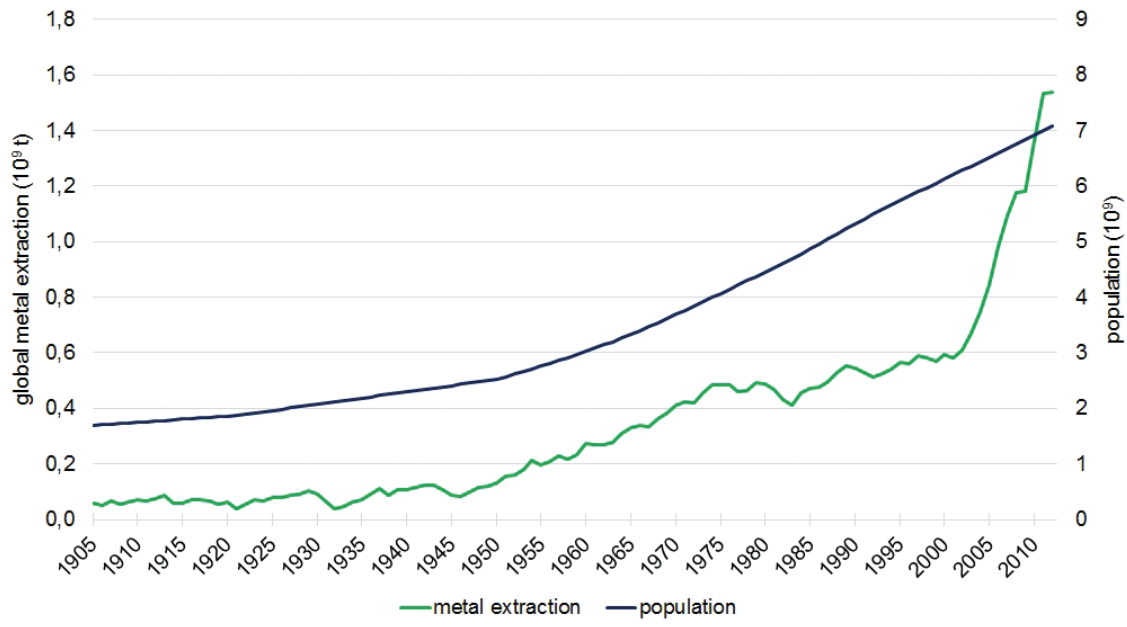

b)

metal extraction and GDP

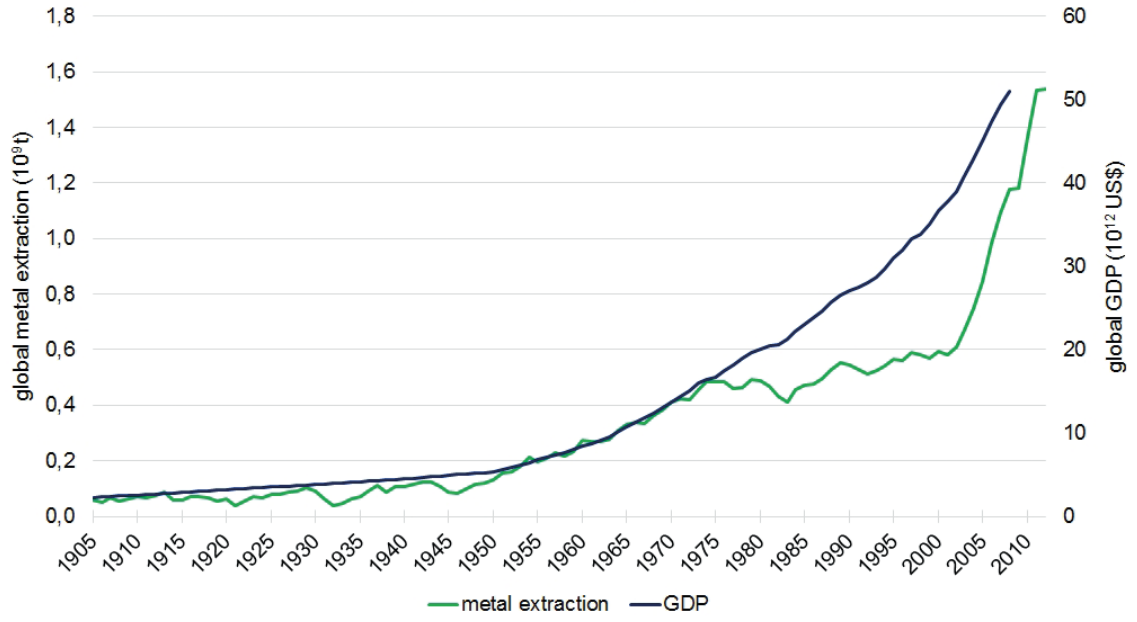

Fig. 1. - a) The extraction of industrially important metals (in billion tons) in the period 1905-2012. All commonly used metals, such as iron, aluminium and copper (83\%, $4 \%$ and 1\%, respectively, of the total in 2012) are included, as are rare metals which make up more than $0.01 \%$ of the total. For those years for which there are no data extrapolation and interpolation has been used. Also shown is the growth in world population in the same period. Data from USGS [3] and the United Nations $[4,5]$. b) The extraction of industrially important metals (as in a) compared with the growth of global GDP (in 1990 International Dollars). Data from USGS [3] and the Maddison Historical Statistics [6].

The last hundred years have also been characterised by a remarkable increase in the use of many rare elements that are indispensable for new technologies. ("Rare" elements are normally defined as those that have a concentration in the earth's crust of less than $0.1 \%$.) The generation, storage, transmission and exploitation of sustainable 


\section{EPJ Web of Conferences}

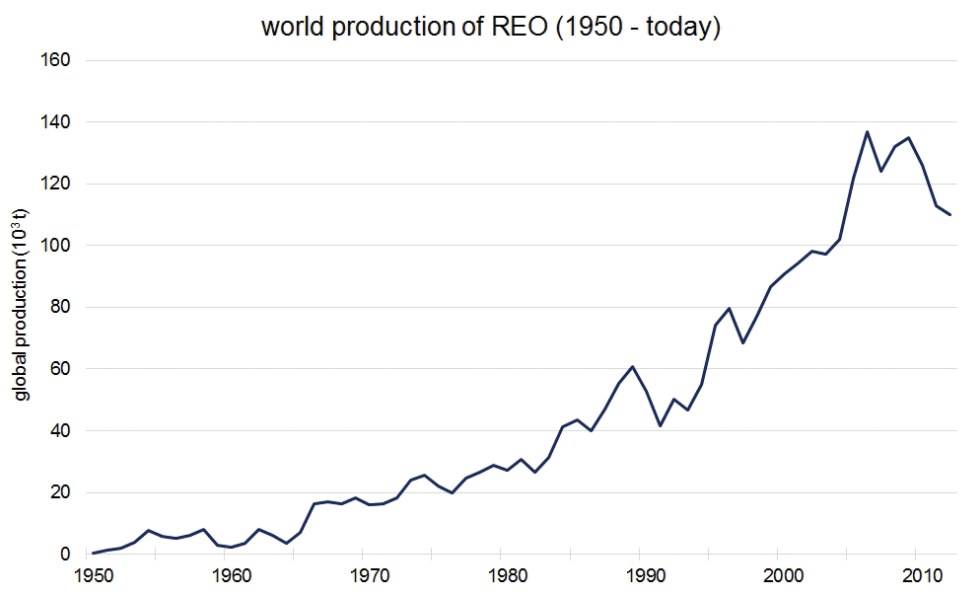

Fig. 2. - The large increase in the annual world production of rare-earth oxides since 1950. Data from USGS [3].

energy forms in the global Energiewende, for example, will require large quantities of rare elements. Besides photovoltaic panels, wind turbines and other applications in the energy sector, other examples of advanced technologies which require certain rare elements are to be found in information and communication technology, alloying for steel and advanced materials, catalysis, nuclear power, lighting and superconductivity. Some of these elements are already characterised by increases in the rate of extraction considerably greater than the average curve in fig. 1. (The latter includes virtually all industrially important metals; the factor 27 quoted above for this data set is largely determined by iron, and to a lesser extent aluminium and copper.) An example is provided by the annual global extraction of rare earth elements (REE), which are mined and traded as the respective oxides (REO). In the first half of the last century annual global REO extraction was on average $\approx 1500 \mathrm{t}$. There has been a phenomenal increase since 1950 , namely by a factor of 80 , as shown in fig. 2 , which is again based on data from the (USGS) [3]. Similarly high, or even higher, growth factors have been recorded for many other rare metals in recent decades. Figure 1 shows that the annual global extraction rate of metals in general, and iron in particular, increased by only a factor of 12 in this period. Hitherto, rare metals had only been used in relatively small quantities for a limited number of applications. Although much of this material will eventually be recovered and re-used, it will - as in the case of the more common metals -increase the "in-use" stock and not be available for recycling in the next few decades.

In recent years concern has been expressed about the potentially difficult, or critical, supply situation that might develop — or in some cases perhaps, has already developed - in connection with mineral resources containing rare elements. These range from alarmist articles in the popular press, to well-researched reports by various bodies, including learned societies, and to papers in the scientific literature. Moreover, at least four 


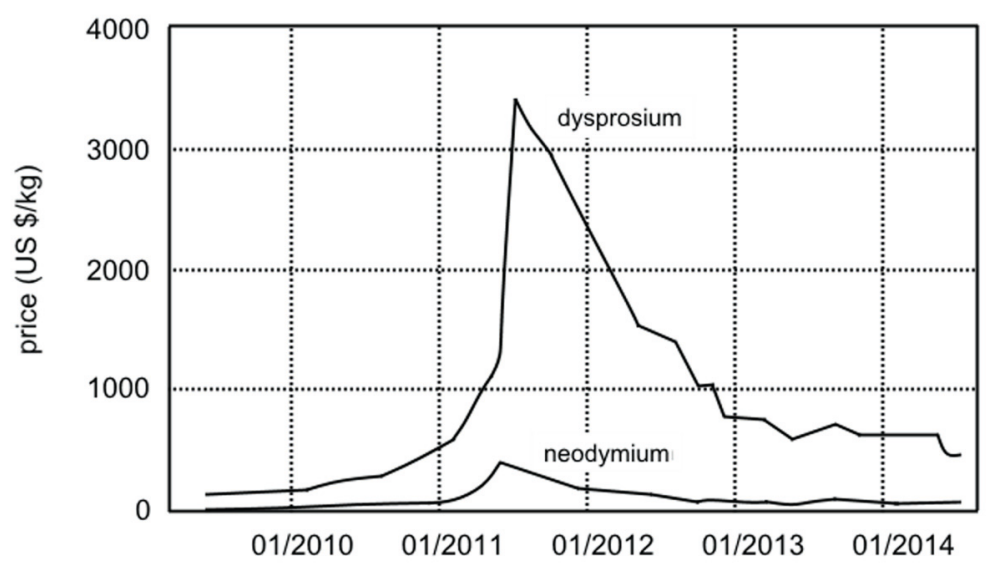

Fig. 3. - Price development for the REE dysprosium and neodymium in the period 2009-2013 (at Chinese port of exit). After [17].

studies have been concerned specifically with energy-related materials [7-10]. Probably most influential of the general reports on this topic was that of the National Research Council (NRC) of the US National Academies in 2008, with the title "Minerals, critical minerals, and the US economy" [11]. There are several criteria, or indicators, which are potentially relevant in determining whether the availability situation of a particular element is likely to become "critical". For example, such a set of indicators and a corresponding procedure for their application have recently been proposed, amongst others, by Graedel et al. [12]. These can be divided into "supply risk", "vulnerability to supply restriction" and "environmental impact". Supply risk, for example can be further divided into indicators covering security of supply (in the political sense), the extraction of the element as a by-product and possible geochemical scarcity due to mineral depletion. Vulnerability to supply restriction includes, for example, the degree of importance of the end product and the substitutability of the element. Achzet and Helbig [13] have recently compared indicators for "supply risk" in these and other studies of "critical" elements. We note in passing that the monopolistic position of China on the REO market in recent years and the price bubble in 2011/12 shown in fig. 3 have given new meaning to the notion of "security of supply": beginning in the early 2000s the Chinese government had imposed restrictions on the export of REE in order to regulate their industry more stringently, in particular from the environmental point of view, and also to conserve supplies of REE for their own manufacturers. The geopolitical connotations of this move gave, however, rise to concern. Figure 3 shows specifically data for the rare-earth elements neodymium and dysprosium [14] that are discussed in sect. 2 in connection with permanent magnet material for wind turbines.

As we have noted, it has become usual in resource studies to refer to "critical" minerals when there is the possibility of restricted availability. Strictly speaking, minerals or the corresponding elements they contain, are not "critical" in themselves, at least not 


\section{EPJ Web of Conferences}

according to the usual dictionary definitions of the word [15], although this form of usage is increasing. Rather, it is the situation, or state of a system, brought about by some attribute or property, which is said to become critical. In the physical sciences the word "critical" is used strictly in connection with a point at which the state of a system converts into a second state described by new parameters, as in a phase transition; hence, "critical point", "critical angle" or "critical mass". The latter is particularly well known as the minimum mass of fissile material required for the occurrence of a nuclear chain reaction. By analogy, "critical" in the minerals context should therefore perhaps only be used to describe the situation that pertains when one or more indicators corresponding to particular attributes or properties cross a (previously determined) threshold value. Particularly confusing is the use of the word "criticality" in this context, which is normally used to describe the behaviour or state of a physical system at and above the critical point.

Whereas Graedel et al. [12] use their indicators to derive semi-quantitatively an overall "criticality score" for each element, indicating that the state of being "critical" is a matter of degree, other groups use the concept "critical" in a similar way to that in the physical sciences. Thus, in a report of the EU Commission on critical raw materials in 2010 [16], two composite indicators "supply risk" und "economic importance" are defined and threshold values for each proposed. Materials exceeding both of these values are designated "critical". Originally, 41 non-fuel materials were investigated in the EU report. The 14 materials designated as "critical" were antimony, beryllium, cobalt, fluorspar, gallium, germanium, graphite, indium, magnesium, niobium, the platinum group metals (PGMs), the REE, tantalum and tungsten. In a second study in 2014 [16], using the same indicators and, most importantly, the same thresholds, borates, chromium, coking coal, magnesite, phosphate rock and silicon "metal" were included. Tantalum, however, dropped out. Space does not permit us to discuss in detail the indicators per se that are used in these studies, but we do return to specific ones below and discuss the effect of mineral depletion generally in the final section.

The present article is concerned with rare elements, mostly metals and often referred to as "minor metals", which might be required for a global Energiewende. For this purpose we assume that sustainable energy forms, in particular, wind and photovoltaics will be providing worldwide $60 \%$ of our total energy supply by 2050 . (It is implicitly assumed that in future electricity generation will play a much more important role in energy production for the heating and transport sectors.) Similarly, we look at nuclear fusion, which may contribute to generating capacity in the second half of the century and also requires rare elements. For each of the three technologies order of magnitude estimates are made of the required "in-use" stock of these elements and the possibility of geochemical scarcity is examined. Moreover, we also discuss the factors, or indicators, which may be of greatest significance for supply risk and vulnerability. These are the substitutability of rare-earth-based permanent magnets in wind turbines and the "extraction as by-product" problem for the minor metals used in thin film photovoltaics as well as for helium required for fusion. The present account is based on some of our recent papers [17-19]. 


\section{2. - Strong permanent magnets for wind turbines}

In the last few years there has been a spectacular rise in the use of certain rareearth elements (REE) in the manufacture of high-field permanent magnets, in particular for the transport and energy sectors. On account of its high remanence and high coercivity the intermetallic compound neodymium iron boride $\left(\mathrm{Nd}_{2} \mathrm{Fe}_{14} \mathrm{~B}\right)$, developed by Sagawa [20] and Croat [21] in 1983 is at present the material of choice for permanent magnets in synchronous motors in a wide variety of applications. This is particularly true for the electric motor in battery electric vehicles (BEVs) and hybrid electric vehicles (HEVs), and for wind turbines. The material also contains normally praseodymium and dysprosium (and/or perhaps terbium). Dysprosium is very important, as it increases the coercivity and extends the temperature range in which the high field can be produced. Hatch [22] gives the composition for various grades of magnet material: whereas, for example, a composition (by weight) of $23 \% \mathrm{Nd}, 8 \% \mathrm{Pr}$ and $1 \%$ Dy gives a maximum working temperature of $80^{\circ} \mathrm{C}, 14 \% \mathrm{Nd}, 5 \% \mathrm{Pr}$ and $12 \%$ Dy extends the maximum working temperature to $240^{\circ} \mathrm{C}$ and trebles the coercivity. Current R\&D on this material focuses on the improvement of magnet production techniques such that smaller quantities of dysprosium can be used ("Dy-saving technology").

Are there alternatives to rare earth-based permanent magnets in electric motors? To answer this question we look briefly at electric motors in general (an electric generator is essentially identical, but the direction of energy flow is reversed). The two main categories of AC motor are the synchronous motor and the asynchronous motor; the latter is also termed induction motor $[23,24]$. Synchronous motors have a rotor which contains either permanent magnets, or electromagnets constructed from copper windings. Induction motors have no such windings on the rotor, which consists of iron and contains a so-called squirrel cage which is usually made from aluminium, or sometimes copper. The stator is the same for synchronous and asynchronous motors and contains copper windings which generate a rotating magnetic field. These two motor types are compared in the schematic diagrams of figs. $4 \mathrm{a}$ and $4 \mathrm{~b}$. As the name suggests, the rotor of the synchronous motor follows this magnetic field synchronously, whereas the rotor of the asynchronous motor turns at a lower rotational velocity (the "slip"). Another electromagnetic phenomenon which can be used for electric motors is the so-called reluctance. This is the property of ferromagnetic material to align itself along magnetic field lines, similar to the magnetic needle of a compass. It is used in a motor with a so-called salient-pole rotor (see fig. 4c). In the stator a rotating magnetic field is created with which the poles of the rotor align. The rotation of the magnetic field in the stator is generated by successively activating and deactivating the copper windings; the rotor then follows. As in the case of the induction motor, no permanent magnets are needed; the rotor just consists of ferromagnetic material such as iron or steel.

Wind generators have been traditionally located on land, but offshore wind generation, i.e. wind turbines located in the sea up to tens of $\mathrm{km}$ from the coast, has great potential, since average wind speed is higher and electricity is generated more continuously than at onshore sites. However, the current cost for offshore wind generators remains quite high 


\section{EPJ Web of Conferences}

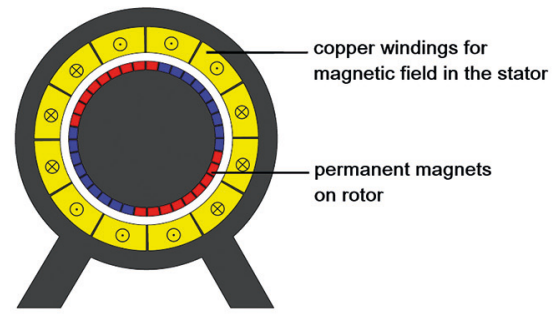

a) Permanent magnet synchronous motor
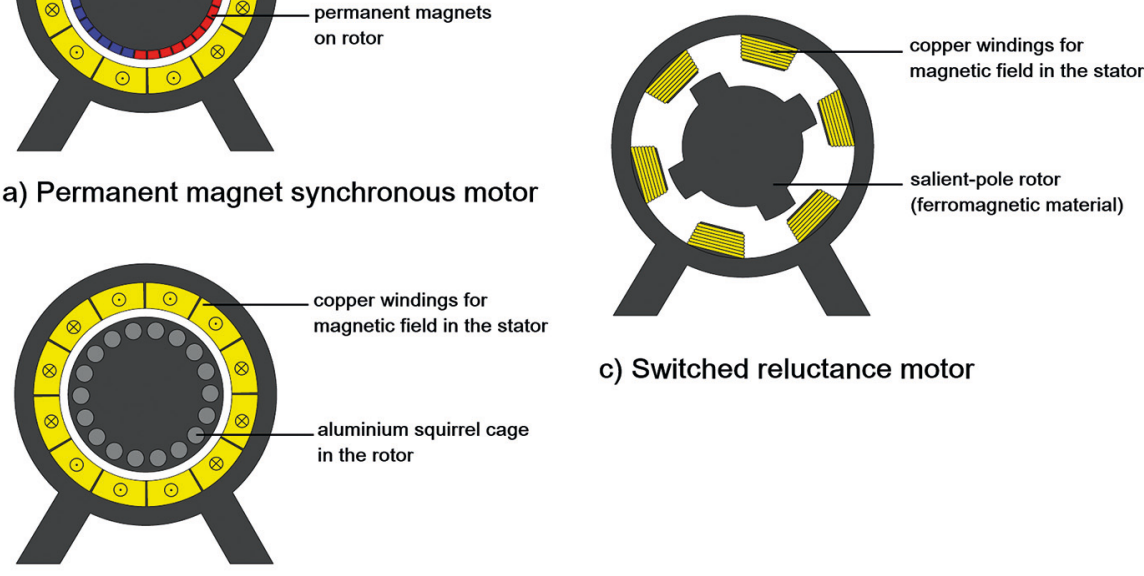

c) Switched reluctance motor

b) Asynchronous, or induction motor

Fig. 4. - Three types of electric machine. After [17].

(because of the additional expenses of installation, servicing and grid connection) which has resulted in an initially slow exploitation of this possibility. Just like the situation for any producer of electricity connected to the grid, the alternating current (AC) from a wind turbine has to be synchronized with the grid. Earlier types of wind generator were designed for only one rotational speed in accordance with the frequency of the grid. For more freedom as to the rotational velocity of the wind turbine, power electronics can be used to link the generator to the electricity grid. Traditionally, gearboxes have been used in wind turbines to connect the slowly turning rotor blades with an induction generator in the so-called nacelle. However, these gearboxes can be quite susceptible to faults, and even to complete failure, giving rise to considerable maintenance needs. Wind turbines without a gearbox ("direct drive") have therefore been on the market since the mid 1990s. Here, the synchronous generator and the electricity grid are connected via an $\mathrm{AC}-\mathrm{DC}-\mathrm{AC}$ converter: the $\mathrm{AC}$ produced in the generator is rectified to direct current (DC) in a first step and then converted back to AC in accordance with the requirements of the grid in a second step. Thus, the rotational velocity of the generator is completely independent of the grid frequency. As this configuration makes the gearbox unnecessary, the technology is particularly advantageous for offshore wind generators where the cost of maintenance is particularly high. Generally speaking, all types of electric machine can be used in wind turbines, but only synchronous generators can be used for direct drive. Hence, the gearless technology was first implemented using synchronous generators with electromagnetic windings on the rotor. Since the size of wind generators has increased 
in order to raise the power output, this technology has led to a considerable demand for copper and a significant increase in the weight of the nacelle. This was the reason for substituting the electrically excited rotor by one with permanent magnets, which allows substantial weight reductions and an increase in efficiency of the generator. However, the price of a generator using permanent magnets is higher (about 25\%) than the alternative with an electromagnet [24].

In summary, direct drive is often the preferred technology particularly for offshore wind parks. For this purpose, permanent magnets can be used, but do not necessarily have to be used. Thus, the development of the relative prices of REE and copper might well decide which of the alternative gearless wind turbine technologies will be utilized in the next few years. In 2013 the market share of direct drive generators was ca. $20 \%$ worldwide [25] and ca. 50\% in Germany [26]. We have not been able to estimate reliably the current market share of permanent magnet technology in direct drive generators.

The REE consist of lanthanum and the subsequent 14 elements of successively higher atomic number, known as the lanthanides. Yttrium and scandium, occurring in the same vertical group of the Periodic Table as lanthanum, are normally included because they have similar properties. In the lanthanide series the $4 f$ shell is successively filled, which gives rise to interesting spectroscopic and magnetic properties, but the chemical properties are very similar, which makes separation difficult. This turns out to be a particular problem for extraction because the rare earth elements never occur singly in the various ores. Rare earths are produced mainly from monazite $\left(\mathrm{CeYPO}_{4}\right)$, as in the Mount Weld mine (Australia), and bastnäsite $\left(\mathrm{CeFCO}_{3}\right)$, as in Bayan Obo (China) and Mountain Pass (California). (All the rare-earth atoms can substitute for the cerium atom.) Both minerals consist almost exclusively of the light rare-earth elements (LREE), yttrium to europium, in particular lanthanum, cerium and neodymium. The corresponding heavy REE, gadolinium to lutetium, are obtained from other minerals, in particular xenotime and the clay deposits in Southern China. The percentage of the much-coveted HREE dysprosium (see below) in xenotime can be as high as $9 \%$. We note in passing that most of the rare-earth deposits also contain uranium and thorium and that because of radioactivity this could constitute a hazard for personnel and for the environment. China has been the major producer of rare earths in the last decades with a 95-98\% market share. Largely because of environmental concerns, which apply not only to extraction but to a lesser extent also to separation, mining activities effectively came to an end in the US and Australia ten years ago. Due to the recent re-opening of the Mountain Pass mine in 2012, the dominance of China is now beginning to decrease and its share of global production fell to $91 \%$ in 2013, according to the USGS [27].

Global mine production of rare earths was 0.10 Mt (as REO) in 2013 [24]. The crustal abundance of cerium, the most plentiful REE, is $83 \mathrm{ppm}$, that of lutetium, the rarest, $0.8 \mathrm{ppm}$ [28]. Reserves are currently estimated to be $140 \mathrm{Mt}$ (= million metric tons), $55 \mathrm{Mt}$ of which are thought to be in China [27]. ("Reserves" are deposits in or on the Earth's crust that can be exploited economically at the present time. "Resources" are defined as deposits in such a condition that economic extraction is potentially feasible. Resources can be further divided into "identified" and "undiscovered". In many cases, 


\section{EPJ Web of Conferences}

the reserves represent only a very small fraction of the resources. Also frequently quoted is the reserves-to-primary production ratio, or "static lifetime", which is in practice not a measure of resource availability, but rather an indication of the time in which mining costs, and possibly prices, are - other factors being equal - likely to remain stable.) The reserves of neodymium and praseodymium would probably be about $20 \%$ of this figure. A very rough guess for the reserves of dysprosium would give about $1 \%$ (1 Mt), since this REE is essentially only a trace element in most bastnäsite and monazite minerals. The extent of the resources is unknown. The USGS states: "Rare earths are relatively abundant in the Earth's crust, but discovered minable concentrations are less common than for most ores. US and world resources are contained primarily in bastnäsite and monazite" and "Undiscovered resources are thought to be very large relative to expected demand" [27].

We now make an order of magnitude estimate for the amount of rare-earth elements, primarily neodymium and dysprosium, that could be required by 2050 as a consequence of a global energy transformation process, or Energiewende. Total global primary energy supply in 2011 was 13,113 Mtoe, or 152,100 TWh, according to the International Energy Agency (IEA) statistics [29]. We assume that this will double by the year 2050, as was roughly the case between 1973 and 2011 [29], to give 300,000 TWh. Furthermore, if renewables provide $60 \%$, we arrive at a contribution of $150,000 \mathrm{TWh}$, after taking into account a $10 \%$ share of renewables in the form of biomass which is used for heating etc. The share of renewables in electricity production would actually have to be much higher in order to reach a $60 \%$ contribution to total energy supply. At this point the assumptions in any case become rather arbitrary, but it should be remembered that we are only attempting an "order of magnitude" estimation! Assuming that wind, solar thermal and $\mathrm{PV}$ will have equal shares and that hydro and various other renewable energy forms will

only contribute $10 \%$, we obtain a figure of 45000 TWh for wind energy. Converting to power and assuming a rather high capacity factor of $50 \%$, we obtain for the "global wind park" 10 TW installed capacity (compared to $282 \mathrm{GWp}$ in 2012). A figure of 100-200 kg REE per MW is normally quoted as the requirement for neodymium-based permanent magnets $[22,30,31]$. This gives a figure of $1-2 \mathrm{Mt} \mathrm{REE}$ for the required in-use stock in the year 2050. This is only a small fraction of the reserves summed over all seventeen REE as currently estimated by the USGS. However, the requirement is for specific rare earths, such as dysprosium, one of the HREE. The number of known, workable deposits for these is decidedly smaller than that for the LREE, as is reflected in the relative prices of neodymium and dysprosium in fig. 2. The estimated 1-2 Mt requirement could be comparable to the total amount of dysprosium metal in the reserves (see above). In connection with permanent magnets Alonso et al. [31] have modelled demand for wind energy using various scenarios, but assume generally a much lower market penetration than in our "order of magnitude" estimate here.

\section{3. - Thin film photovoltaic modules}

Globally, about $30 \mathrm{GWp}$ of new photovoltaic (PV) capacity was installed in 2012 [32]. The thin film materials cadmium telluride, amorphous silicon and copper indium gallium 


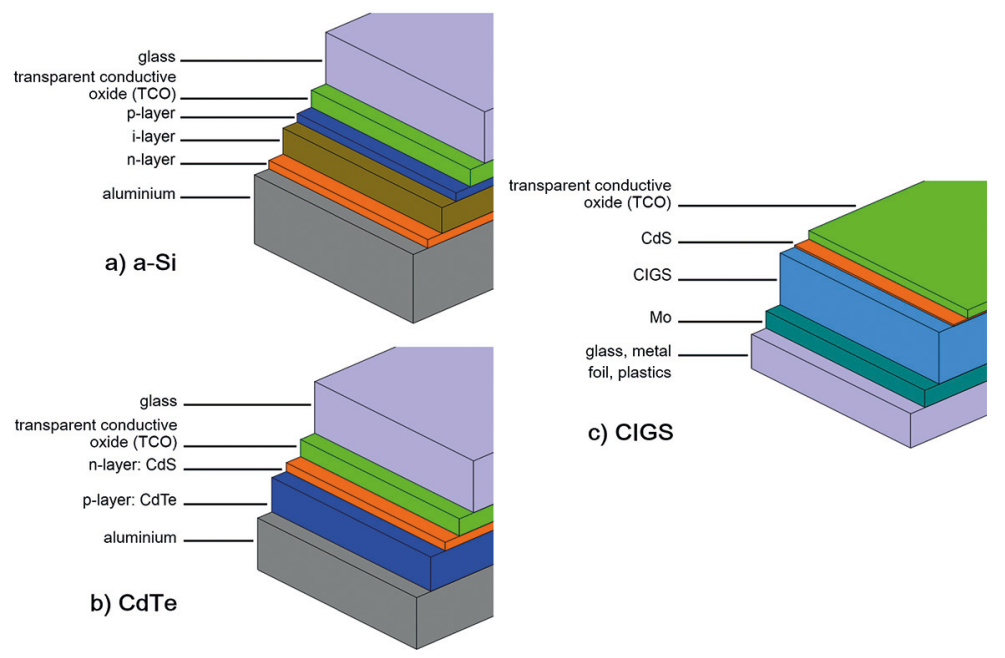

Fig. 5. - Thin film photocells, a-Si, CdTe, CIGS. After [17].

diselenide $\left\{\mathrm{Cu}\left(\mathrm{In}_{x} \mathrm{Ga}_{1-x}\right) \mathrm{Se}_{2}\right\}$, or $\mathrm{CI}(\mathrm{G}) \mathrm{S}$, had PV market shares in that year of $6.3 \%$, $4.5 \%$ and $1.1 \%$, respectively [32]. At the time of writing, figures for 2013 are not yet available. Schematic diagrams of the three cells are shown in fig. 5. Note that the thin film of transparent conducting oxide (TCO) in all three cases is usually indium tin oxide (ITO), the latter being a ubiquitous material in many display and conductive coating applications. Molybdenum (Mo) is used as a substrate for CIGS cells, because of the high temperature required in the production process. In general, thin film modules have lower efficiencies than those based on crystalline silicon technology, but are cheaper to manufacture. Module efficiencies are normally given as $12-14 \%, 12-14 \%$ and $6-9 \%$ for CdTe, CIGS and a-Si, respectively, compared with a value of up to $20 \%$ for single crystal silicon. We note, however, that "best" module efficiencies are still increasing for CdTe and CIGS: $17.0 \%$ [33] and 15.7\% [34], respectively, have recently been reported. Of the thin film modules CIGS has allegedly the highest manufacturing costs. In the context of the present article it is important to note that all five elements concerned are by-products in the production process of a primary resource. For cadmium and indium this is zinc; for gallium, mainly aluminium; for selenium and tellurium, copper or lead [35]. In fact, they are extracted exclusively on this basis; there are no cadmium mines, for example, because there are few or no minable deposits of this element. By-products can be very important for the profitability of a mine, i.e. for the extraction of the primary product. Once the ore has been mined, the additional expense of extracting low concentration by-products during mineral processing operations ("beneficiation") is relatively low. On the other hand, the fact that a rare metal is extracted as a by-product can entail a certain supply risk, if demand for the host mineral or element suddenly falls, as Graedel et al. [12] have pointed out. We now briefly review the long-term supply risk for these 


\section{EPJ Web of Conferences}

TABLE I. - Rare elements for thin film solar cells. Note that, where appropriate, the figures refer to the year 2011, unless otherwise stated. Annual production includes secondary material. Sources: refs. [27,35-42].

\begin{tabular}{|c|c|c|c|c|c|}
\hline $\begin{array}{c}\text { crustal } \\
\text { abundance } \\
\text { (ppm) }\end{array}$ & cadmium & tellurium & indium & gallium & selenium \\
\hline $\begin{array}{c}\text { "host" } \\
\text { element }\end{array}$ & $\mathrm{Zn}$ & mainly Cu & $\mathrm{Zn}$ & mainly Al & mainly Cu \\
\hline $\begin{array}{c}\text { reserves, } \\
\text { resources } \\
(\mathrm{Mt})\end{array}$ & $0.64,5.0^{\text {(a) }}$ & $0.024,0.1^{(\mathrm{a})}$ & $\begin{array}{c}0.011^{(\mathrm{b})} \\
(2008)\end{array}$ & $1.0^{(\mathrm{c})}$ & $0.092^{(\mathrm{b})}$ \\
\hline $\begin{array}{c}\text { annual } \\
\text { production } \\
\text { (kt) }\end{array}$ & 28 & $\approx 0.5$ & 1.8 & 0.31 & 3.5 \\
\hline $\begin{array}{c}\% \text { thereof } \\
\text { for solar }\end{array}$ & 0.6 & 38 & 1 & 2 & 1 \\
\hline
\end{tabular}

(a) Estimated.

(b) Reserves, resources unknown.

(c) Resources, reserves proprietary information.

five elements with the help of table I. (Note that, for consistency, most of the data in table I derive from the year 2011, if available.)

The metal cadmium is used mainly for nickel-cadmium batteries, although inside the $\mathrm{EU}$ the sale of new batteries is forbidden (except for some special applications) because of its toxicity. Li-Ion batteries are in any case replacing $\mathrm{NiCd}$ batteries in many consumer applications, because of the higher energy density, although the price is approximately double. As noted above, cadmium is a by-product in zinc mining, where it substitutes atomically to the extent of about $0.3 \%$ for zinc in sphalerite $(\mathrm{ZnS})$. Other rare elements similarly present in sphalerite in concentrations up to a few tenths of a percent include gallium, germanium and sometimes indium. The module manufacturer First Solar has recently instituted "the industry's first comprehensive, prefunded module collection and recycling program", presumably in response to concerns about the toxicity of cadmium. The USGS gives a figure of $640 \mathrm{kt}$ for the reserves corresponding to a reserves-to-primary production ratio, or static lifetime, of 28 years.

The situation with regard to the very rare metalloid tellurium could perhaps be described as "critical". The source of $90 \%$ of tellurium is copper ore, in which the element may be present in a concentration of up to $1 \times 10^{-6}$ relative to the copper. (Other by-products of copper mining may include gold, selenium, antimony and the platinum group metals.) A small amount of tellurium is also obtained as by-product in the mining of zinc, lead, gold, nickel and platinum. Potential primary ore sources have also been identified. Tellurium and the other by-products are extracted from the 
anode slime produced in electrolytic copper refining. (We note that the leach/solvent extraction/electrowinning technique for processing copper does not capture tellurium and selenium.) Of all five rare metals considered in this section it is only tellurium for which solar cell manufacture consumes a very significant part of annual production: $38 \%$, compared to $0.6 \%, 1 \%, 2 \%$ and $1 \%$ for $\mathrm{Cd}$, In, Ga and Se, respectively. Other uses include thermoelectrics (30\%), alloying (15\%) and vulcanisation (5\%). Tellurium reserves of $24 \mathrm{kt}$ correspond to a reserves-to-primary production ratio of 50 years.

Indium, like cadmium, is mainly obtained from zinc deposits, where it substitutes for zinc in sphalerite $(\mathrm{ZnS})$, but at the most in a concentration of $0.01 \%$. The largest producer of primary indium is China, which maintains an export quota. Substantial quantities of indium derive from recycling the material which is left over from the rather inefficient process of sputtering ITO (indium tin oxide) layers [37]. Substantially more than $50 \%$ of indium produced is used for ITO layers in liquid crystal displays (LCDs), plasma displays, touch panels, organic light-emitting diodes (LEDs) and solar cells. Other uses include solders and alloys, as well as III-V semiconductors for LEDs and laser diodes. To a current (2011) indium requirement of $16 \mathrm{t}$ for CIGS cells we have to add about $6 \mathrm{t}$ for (thinner) TCO layers in all three thin film solar cells Presumably because of the difficulty of obtaining reliable data, the USGS currently does not quote the global reserves; in 2008 a figure of $11 \mathrm{kt}$ was given.

Gallium is extracted almost exclusively from the aluminium ore bauxite, but with a very small amount coming from sphalerite. Gallium production increased by $19 \%$ in 2011 . Since the majority of gallium is used for the manufacture of GaAs, and to a lesser extent, GaN devices, this reflects the currently expanding market for "smart" phones [39]. In an analogous way to indium we estimate the amount of gallium required for the manufacture of CIGS solar modules in 2011 as 5 t, corresponding to $1-2 \%$ of annual production. The USGS [27] makes no attempt to estimate the gallium reserves, pointing out that only a certain proportion of the gallium in bauxite and sphalerite is extractable, but the details are proprietary. The world resources of gallium in bauxite are estimated to be $1 \mathrm{Mt}$.

The situation with regard to selenium, a non-metal, is very similar to that of tellurium: not only does it come between sulphur and tellurium in the same group of the periodic table, but it is also an important by-product in copper mining and extraction. With a crustal abundance of $0.05 \mathrm{ppm}$ it is, however, not quite as rare as tellurium. Note that the concentration of by-product - selenium, tellurium, gold and antimony, etc. depends on the copper ore. The main uses of selenium are alloying (40\%), glass (25\%) and agriculture (10\%); we estimate that solar cell manufacture required only $32 \mathrm{t}$, or about $1 \%$, in 2011. Reserves are given as $92 \mathrm{kt}$ [27], assuming that copper remains virtually the only source, which corresponds to a reserves-to-production ratio of about 30 years. As in the case of tellurium, the USGS gives no figure for the selenium resources. Note that nickel also contains selenium, as does coal (between 0.5 and $12 \mathrm{ppm}$ ). The latter is probably a potentially large-scale, if at present uneconomical, source [27].

As in the case of wind power, we can - using similar assumptions - make an order of magnitude estimate of the amounts of these five elements that could be required by 2050 as a consequence of global energy transformation process. We assume that there is 


\section{EPJ Web of Conferences}

a $60 \%$ market penetration by renewables, giving a total of $150000 \mathrm{TWh}$, and that wind, solar thermal and PV will have equal shares, besides $10 \%$ for various other renewable energy forms. This gives a figure of $45000 \mathrm{TWh}$ for PV. Very arbitrarily, we give CdTe and CIGS a one third share of the PV market each. After converting to power and assuming a (generous!) $25 \%$ capacity factor, $7 \mathrm{TW}_{\mathrm{p}}$ for each type of module is obtained. Using literature values for the amounts of the five elements required per $\mathrm{TW}_{\mathrm{p}}[35,41]$, the resulting material requirements for the "in-use stock" in 2050 would be $6 \times 10^{5} \mathrm{t}, 7 \times 10^{5} \mathrm{t}$, $2 \times 10^{5} \mathrm{t}, 5 \times 10^{4} \mathrm{t}$ and $3 \times 10^{5} \mathrm{t}$ for cadmium, tellurium, indium (including ITO), gallium and selenium, respectively. It is unlikely that there will be availability problems for cadmium due to mineral depletion, but the figure of $7 \times 10^{5}$ t for tellurium, for example, is a factor 20 higher than the reserves(USGS), and probably greater than the identified resources. It may be possible to reduce the amounts of the elements required relative to the power rating by increasing the module efficiency, but this would probably not be more than a few percent. More promising would be the manufacture of modules with substantially reduced film thicknesses, which is thought to be technically possible [35]. We should remind ourselves, however, that one of the assumptions made above, namely, that thin film technology rather than crystalline silicon technology dominates in 2050, is rather optimistic. Despite the recent improvements in the module efficiency of thin film devices, the actual market share and hence the demand for these metals in the energy sector may remain quite small

\section{4. - Nuclear fusion}

Figure 6 shows a schematic of the international ITER experiment currently under construction in Cadarache, France. The aim of ITER is to demonstrate the viability of producing electricity from nuclear fusion for commercial purposes. However, even if ITER proves to be a success, numerous technical issues will still have to be solved first in a demonstration power plant. Fusion reactors could make a substantial contribution to electricity supply in the second half of this century. The fuels required are lithium, actually lithium-6, from which the necessary tritium will be bred in situ using the fusion neutrons, and deuterium. The schematic of such a power plant in fig. 7 also shows the tritium breeding system. Neutrons will, however, be lost through parasitic absorption in the structural materials of the reactor. To achieve tritium self-sufficiency, it will be necessary to employ a neutron multiplier, such as beryllium or lead, producing further neutrons via $(\mathrm{n}, 2 \mathrm{n})$ reactions in the so-called blanket of the reactor. In a previous publication [18] we have shown that, as expected, deuterium will never become a problem from the supply point of view. It is present to the extent of 1 part in 6400 (156 ppm) in naturally occurring hydrogen and for fusion purposes would probably be extracted by electrolysis of heavy water obtained via isotopic exchange. Lead is not considered to be a serious problem either, since the identified resources lie in the Gigaton range. The supply situation for lithium could become critical, however, depending to what extent the metal will be used in future for lithium-ion batteries, in particular for electric vehicles. Beryllium is also a potential problem. In the next paragraph we examine the 


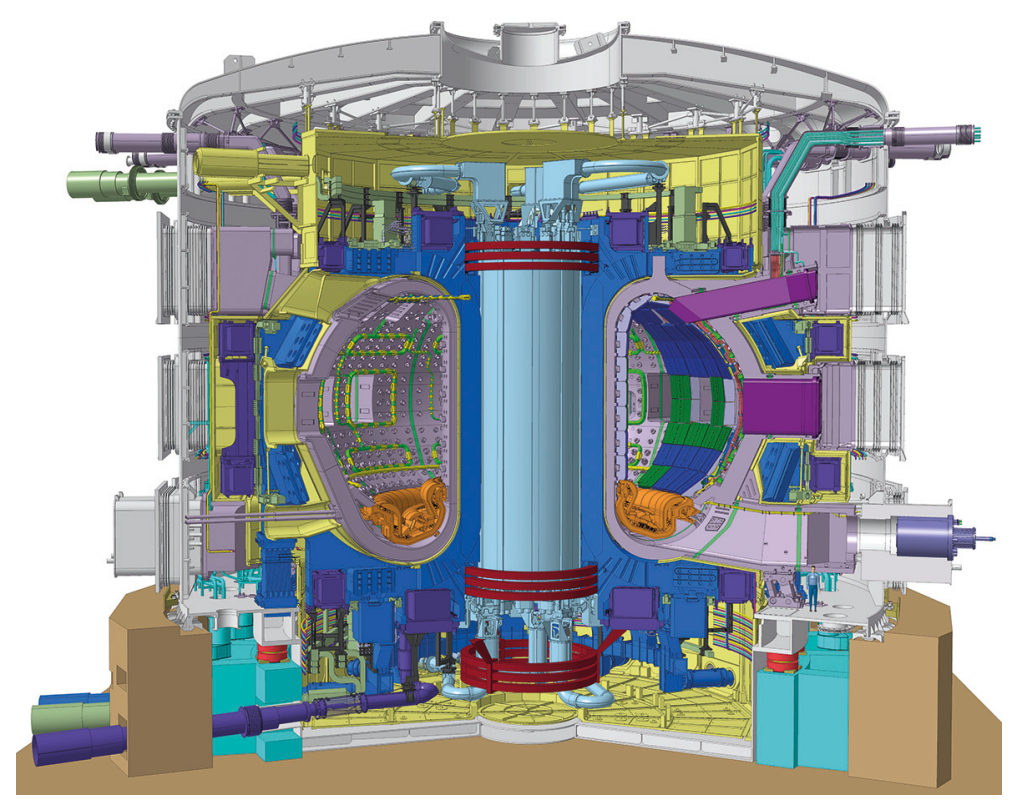

Fig. 6. - The international ITER fusion experiment currently under construction. ITER is based on the "tokamak" principle of magnetic confinement, in which the plasma is contained in a doughnut-shaped vacuum vessel. The fuel - a mixture of deuterium and tritium, two isotopes of hydrogen - is heated to temperatures in excess of 150 million ${ }^{\circ} \mathrm{C}$, forming a very hot plasma. Strong magnetic fields are used to keep the plasma away from the walls; these are produced by superconducting coils surrounding the vessel, and by an electrical current driven through the plasma (see the contribution by Ongena in the present Volume). Source: ITER Organisation, Cadarache.

availability of lithium and beryllium and try to assess future requirements of lithium for electric vehicles. The lithium and beryllium requirements for fusion are then summarised, assuming that this energy carrier will make a substantial contribution to energy supply sometime in the second half of this century. We note here that lithium-6, deuterium, beryllium and lead are actually "fuels" and are consumed in the nuclear fusion reactor. Subsequently, helium and niobium, which are also materials required for fusion reactors, but not "fuels", will be examined.

The USGS gives global lithium reserves and resources as $13 \mathrm{Mt}$ and ca. $40 \mathrm{Mt}$, respectively [27]; the crustal abundance is 20 ppm [28]. In 2010 the USGS increased its estimate of reserves largely as a result of a re-assessment of the potential of the salt brines under the salars in South America and China. Lithium reserves are divided up approximately 2:1 between brines and minerals, mainly spodumene, a lithium aluminium silicate. In seawater the lithium concentration is on average $0.17 \mathrm{ppm}$, or $0.17 \mathrm{~g}$ per ton. Multiplying by the total volume of seawater gives a lithium content of $226000 \mathrm{Mt}$. Annual production in 2012 was $37000 \mathrm{t}$ (recycling is insignificant); the ceramics and glass industry remains the major user with $30 \%$, followed by batteries, $22 \%$. Beryllium is significantly rarer with 


\section{EPJ Web of Conferences}

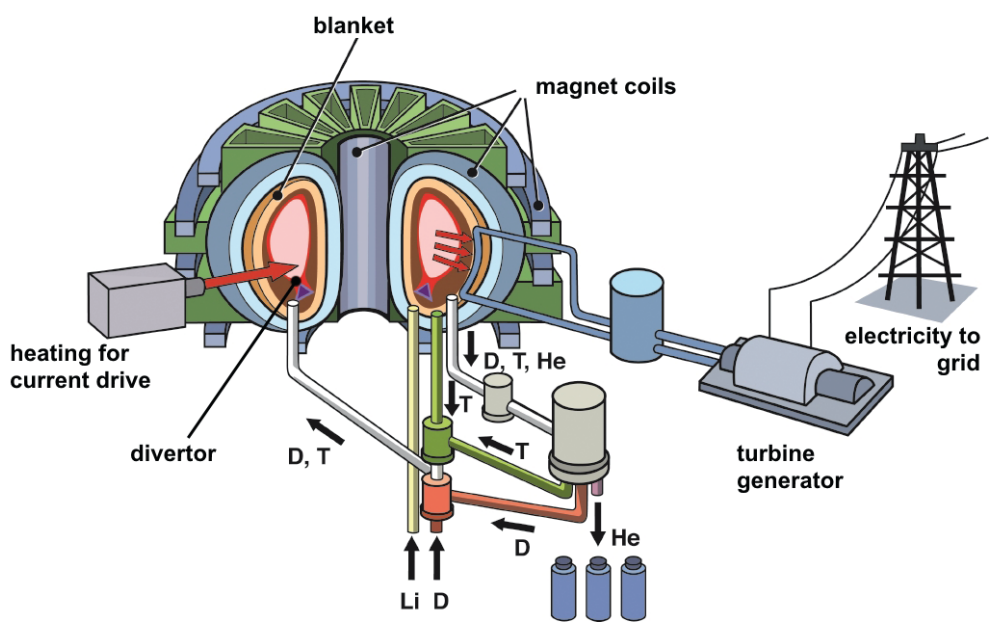

Fig. 7. - Schematic of a possible future fusion power plant. Source: Max-Planck-Institut für Plasmaphysik (IPP).

a crustal abundance of $2.8 \mathrm{ppm}$, but neither metal is as rare as, for instance, tellurium (see above) or platinum [28]. Despite its presence in over 90 known minerals, only beryl (a beryllium aluminium silicate) and bertrandite (a beryllium sorosilicate hydroxide) occur in minable concentrations. The USGS does not give a figure for the reserves, but estimates the resources as $80 \mathrm{kt}$, although it is not clear from where this value comes. Annual mine production was $230 \mathrm{t}$ in 2012 , with a further $70 \mathrm{t}$ probably coming from recycling. Craig et al. [28] note "The restriction on production is two-fold. First, deposits are small and quite expensive to work. Second, the separation of beryllium is a very expensive and exacting process." Most of the world's beryllium currently derives from a single American supplier.

How much lithium will be needed for non-fusion purposes in coming years? It is currently accepted that batteries, for both full battery electric vehicles (BEV) and hybrid electric vehicles (HEV), will lead to a massive increase in demand, and this will dominate the market in the next few decades. We deliberately present a "worst case" scenario: If we assume that i) the whole global vehicle fleet of approx. $10^{9}$ units is "electrified" over the next 40 years linearly in time, ii) plug-in hybrids with $16 \mathrm{kWh}$ batteries are the system of choice (completely electric vehicles will require larger batteries), iii) $400 \mathrm{~g}$ Li are required per $\mathrm{kWh}[43]$ and iv) recycling takes place after ten years with $80 \%$ efficiency, then approximately $10 \mathrm{Mt}$ lithium will be required by 2050, of which about half would probably result from recycled material. (At present, practically no lithium is recycled.) A figure of about $5 \mathrm{Mt}$ is lower than the present known reserves $(13 \mathrm{Mt})$, and considerably lower than the identified resources. If lithium-ion batteries were also to find large-scale application in electricity storage for industrial and domestic purposes, then there would be greater cause for concern. 
How much lithium and beryllium would be required if fusion were to make a substantial contribution to electricity supply? Here, we use data from the European DEMO reactor study [44] as well as the results of calculations reported in ref. [18]. In one of the two reactor concepts the blanket consists of lithium ceramic pebbles as breeder material and beryllium pebbles as multiplier (He-cooled pebble bed - HCPB) with 2.4 GW fusion power and $1 \mathrm{GWe}$. Using the same figure as for wind and PV above, namely $45000 \mathrm{TWh}$, we arrive at a total of 5140 power stations that will be required globally. (In our previous paper we made similar estimates but for a lower contribution of fusion to global electricity supply [18].) These would consume $1.5 \mathrm{kt}$ lithium-6, for which $18.7 \mathrm{kt}$ of natural, nonenriched lithium would be required annually (the so-called burn up). Thus, the present lithium reserves of $13 \mathrm{Mt}$ (see above) would correspond to a reserves-to-production ratio of 695 years, if used only for fusion. The sum of the lithium inventories for all power plants would be $18.5 \mathrm{kt}$ lithium-6, corresponding to $231 \mathrm{kt}$ natural lithium and representing about $2 \%$ of the reserves. This situation for lithium might be regarded as critical, but mainly due to the possible demand for electric vehicles. On the other hand, if we consider the potential of seawater, then there is enough lithium, at least theoretically, for the operation of 5140 power plants for 12 million years! The beryllium burn-up in $5140 \mathrm{HCPB}$ power plants would be $524 \mathrm{t}$ annually and the initial loading $616 \mathrm{kt}$, probably exceeding considerably the putative resources. Whereas it is conceivable that the first generation of fusion power plants would use a beryllium multiplier, a scarcity of beryllium due to mineral depletion (or perhaps better expressed: due to the apparent exhaustion of conventional deposits) might encourage the development of a breeding blanket with a $\mathrm{Pb}$-Li eutectic acting both as breeder and nuclear multiplier, as in the helium-cooled lithium lead (DEMO-HCLL) concept [44].

Two further elements will probably be required in large quantities in future fusion reactors, but not as "fuels". Helium, on the assumption that "high temperature" superconductors will not be available, will be needed as cryogenic medium and as coolant in the power conversion system. Niobium is an important constituent of the superconducting material comprising the magnetic field coils. Nuclear fusion actually produces helium, not only in the breeding and fusion reactions but also in the beryllium multiplier. However, it is unlikely that the losses - even with efficient recovery systems - would be compensated by the helium produced. After briefly describing the origin of terrestrial helium and the current supply situation, we estimate possible helium requirements for fusion, before turning our attention, very briefly, to niobium.

Although helium is the second most abundant element in the universe, the average concentration in the Earth's crust is probably not even in the ppb range, and in the atmosphere it is only $5.2 \mathrm{ppm}$ by volume $[45,46]$. The majority derives from the nuclear decay of uranium and thorium. Most of the helium thus created has diffused to the surface and escaped into the atmosphere over the last 4 billion years. A small fraction, however, has been trapped by impermeable layers of rock. Natural gas, consisting mainly of methane, also collects in such geological constellations, so that helium for commercial use is normally produced from natural gas, where it is a minor component in concentrations up to, but very rarely exceeding, about one per cent [47]. It can be calculated that about 


\section{EPJ Web of Conferences}

$1 \times 10^{14} \mathrm{t}$ helium has passed into the Earth's atmosphere since the formation of the planet. Yet the concentration of helium in the Earth's atmosphere (5.2 ppm) corresponds to a total of only $3.5 \times 10^{9} \mathrm{t}$, and is presumed to have remained more or less constant on the geological time scale. This means that about $10^{14} \mathrm{t}$ must also have been lost from the upper atmosphere during this period. The reason is that the magnetosphere contains a very dilute helium-hydrogen plasma, the ions of which spiral along the Earth's magnetic field lines. Whereas the latter normally remain closed, the interaction with the solar wind above the poles causes magnetic reconnection to take place, so that the field lines open up and the plasma can escape along them into interplanetary space (the polar wind) [48]. We note, firstly, that only a very small fraction, less than $10^{-7}$, of the total amount of the radiogenic helium formed in the Earth's crust in the last four billion years has accumulated, fortuitously and fortunately, in appropriate geological strata. Secondly, despite this huge amount of helium that has passed through the Earth's atmosphere, the annual rate of production in the crust is only about $3 \times 10^{3} \mathrm{t}$ per year. There is no prospect of tapping into this supply, because of the high degree of dispersion of the sources, i.e. the radioactive nuclei in various minerals.

The total helium reserves and the identified resources as of 2013 are given by the USGS [27] as 1.3 Mt and 8.5 Mt, respectively, (i.e. a factor of several hundred less than the amount of helium in the atmosphere.) The US, Qatar, Algeria and Russia have the largest resources at their disposal. Current (2013) global production is $23 \mathrm{kt}$ per year, of which $65 \%$ were extracted in the United States [27]. A further $8 \mathrm{kt}$ were withdrawn from the Clifford Field storage reservoir. New helium plants in conjunction with liquid natural gas production will shortly come online in Algeria and Qatar. Reliable figures for usage are only available for the US, but are not expected to be vastly different globally. For the year 2011 the figures were: Cryogenics (in particular magnetic resonance imaging, but also research in the physical sciences) $32 \%$, pressurising and purging $18 \%$, welding (as protective gas) 13\%, leak detection 4\%, breathing mixtures $2 \%$ and others (including party balloons!) $13 \%$ [46]. Helium supply in the last few years has been characterised by shortages and by price rises [49]. The latter, however, have been moderate because there is not a free market in helium. The price is essentially determined by the price at which the US Bureau of Land Management (BLM) sells off the helium from Clifford Field. In the next few years, the supply situation will undoubtedly change due to the new helium production facilities outside the US described above, but also - in the opposite sense - by the recommendation of the National Academies of Science in the 2010 report not to run down the federal reserve as originally envisaged by the US Congress. This is a complicated issue, but it suffices here to note that there is at present no scarcity of helium due to depletion. However, the quantity of helium stored in natural gas deposits is finite: the danger exists that natural gas will be exhausted in the next 100 years or so without the helium being extracted and perhaps conserved for future generations.

Following ref. [19], and taking into account the paper of Clarke and Cai [50], we estimate the helium losses in a future fusion power station. Based on the planning for ITER [51], it would appear that the cryogenic system for DEMO, including the onsite infrastructure, would require about $34 \mathrm{t}$ helium. The necessary helium inventory in 
the power conversion system of DEMO has been estimated at about 23t [52], giving a total helium inventory of about $60 \mathrm{t}$. The existing evidence (other large systems such as CERN, the planning for ITER, design optimisation)suggests that annual losses could be about $2 \mathrm{t}$ per year. On the plus side, the combined helium production in DEMO from the breeding reaction, the fusion reaction and, in the case of the HCPB, the multiplier would be about $0.6 \mathrm{t}$. Since a lead multiplier does not produce $\alpha$-particles, the figure for the HCLL variant is lower at about 0.4 t. The current (2013) global helium production rate from both natural gas and the US reserve of $31 \mathrm{kt}$ p. a. (see above) corresponds to a reserves/resources-to-production ratio, or static lifetime, of 280 years. What difference would fusion make? We use the scenario above: 5140 power plants (similar to DEMO HCPB or HCLL), which would provide 45000 TWh p. a. some time in the second half of the century. The total helium inventory of all power plants is $0.3 \mathrm{Mt}$, which is about $4 \%$ of the identified global resources. Annual losses would be $10 \mathrm{kt}$, decreasing the resourcesto-production ratio to 210 years. Fusion as a non-sustainable consumer of helium would thus exacerbate an already difficult situation. Potentially more serious is the effective exhaustion of helium in the Earth's crust as a result of mankind's unslakeable thirst for "cheap" fossil fuel. We can only emphasise again, as have Nuttal et al. [46] in their Nature article, that natural gas will soon be drastically depleted without the helium being extracted and conserved. Mankind would then only have recourse to the expensive and logistically complicated production of helium from the atmosphere [53].

Finally, we turn to niobium which is required in fusion for the superconducting magnetic field coils consisting of $\mathrm{Nb}_{3} \mathrm{Sn}$ and/or NbTi. This rare metal with a crustal abundance of $10-20 \mathrm{ppm}$ is mainly extracted from the mineral pyrochlore $(\mathrm{Na}, \mathrm{Ca})_{2} \mathrm{Nb}_{2} \mathrm{O}_{6}$ in Brazil. It also occurs together with tantalum (same group of the periodic table) in the mineral columbite-tantalite, $(\mathrm{FeMn})(\mathrm{Ta}, \mathrm{Nb})_{2} \mathrm{O}_{6}$, which is mined mainly in Australia for its tantalum content and sometimes referred to as "coltan" [28]. The USGS gives the current global niobium production as $69 \mathrm{kt}$; the reserves are estimated to be at least $4 \mathrm{Mt}$ [27], resulting in a reserves-to-production ratio of at least 60 years. The extent of the resources is unknown. Main uses at present are for special steels and superalloys; the amount of metal required at present for manufacturing Nb-based superconductor appears to be very small in comparison, but no exact figures are available. The ITER experiment requires about $175 \mathrm{t}$ niobium for its toroidal and poloidal field coils [54]. Assuming DEMO will be similar and rounding up to $200 \mathrm{t}$ per reactor, the $45000 \mathrm{TWh}$ scenario for fusion above would require an in-use stock of $1 \mathrm{Mt}$ niobium, i.e. about a quarter of the currently identified reserves. Lack of information concerning the resources and, on the fusion side, concerning end-of-life recycling prevent us from drawing any conclusions about the niobium situation at present.

\section{5. - Mineral depletion and scarcity}

Of the rare elements considered here, it is probably only helium that will become scarce in the course of this century due to its physical depletion in the Earth's crust. Helium is contained only in accessible quantities in natural gas deposits, as has been 


\section{EPJ Web of Conferences}

discussed in sect. 4. We use the words "scarce" and "scarcity" with care, since they are concepts that can only be defined in economic terms. Scarcity pertains when a limited, or decreased, availability of a particular resource leads to increased prices on a real, inflation-adjusted basis. In most situations supply will match demand: If the mineral resource is perceived as effectively inexhaustible, then output will expand until the extra cost of producing just one more ton is covered by the market price. If the consumer is not in a position to pay the price for the amount he needs, he switches to another metal or material, which is referred to as "substitution". The consumption of exhaustible natural resources (or of natural resources that are deemed exhaustible) is somewhat different because the so-called Hotelling rent [55] may also contribute to the costs and thus to the market price. Space does not permit us to discuss Hotelling theory here. Even if mineral depletion does not play a role, however, various other factors can cause scarcity and lead to the designation "critical" discussed in sect. 1. Such factors, both on the supply and demand sides, are sudden strong economic growth in a country or region, the rapid introduction of new technologies, monopolistic situations, speculation, politically motivated embargos (the "security of supply" issue) and extraction as a by-product(as described in sect. 3).

Mineral depletion may be deemed to have occurred when mining companies are forced to exploit deposits of increasingly lower grade, or to mine under more difficult conditions, e.g. at greater depth, so that production costs increase. Due to the introduction of new, more efficient techniques for prospecting, mining and processing of ores these costs can in principle be counterbalanced. For most of the 20th century exactly this situation pertained: real (inflation-adjusted) prices for mineral commodities fell steadily. A further ramification of this technological progress in extraction is the fact that - in the course of time - resources have been re-classified as reserves and undiscovered resources as identified resources. The discovery of new deposits of course also plays an important role. Copper is an interesting example [27]: in 1970, identified and undiscovered world copper resources were estimated to consist of $1.6 \mathrm{Gt}$; the reserves were $0.3 \mathrm{Gt}$. Since then, the world has produced $0.4 \mathrm{Gt}$ copper and the reserves are now estimated to be $0.7 \mathrm{Gt}$, and the global resources possibly $3 \mathrm{Gt}$ !

If advances in mining technology cannot compensate for lower grades and more difficult conditions, then mineral depletion will cause, or contribute to, scarcity. We note that the downward trend in prices in the 20th century has reversed in the last 10-15 years, despite financial crises and zero economic growth in many countries. The copper price, for instance, is at the time of writing (2014) four times higher than it was in 2000. Does this mean that mineral depletion is already giving rise to scarcity? Or has the massive increase in demand for raw materials in Southeast Asia been the decisive factor? These are difficult questions to answer. All we can say is that mineral depletion could already be affecting the market in some instances, but it is unlikely that beryllium, indium, dysprosium and tellurium, discussed in sects. $\mathbf{2 - 4}$, are affected. We note that the latter three are actually by-products (even dysprosium, as one of the rarer REE), which will probably be a more important factor in determining scarcity in the near future. Moreover, all four have been characterised by demand-driven price oscillations in 
the last few years, which are probably a greater cause for concern at present. Tellurium, for which CdTe thin film photovoltaic technology comprises a major application, has been particularly vulnerable to these fluctuations. Despite the low reserves/resourcesto-primary production ratios in table I there does not seem to be a serious danger of depletion on a scale that would result in serious consequences in the next few decades, or even in the next one to two centuries. Even if the requirement for these metals is as high as the "order of magnitude" estimates above suggest, it is only in the case of tellurium that the demand from energy applications could cause substantial supply risks. (Not enough is known about beryllium in order to judge the situation properly for this element.) Moreover, these estimates are very optimistic as to the extent of the global Energiewende. The possibility of substitution also exists: silicon technology might even win out completely in the case of photovoltaics, for example.

Even in a non-regulated market complete exhaustion of a particular mineral will never occur. The quantity of even the rarest elements present in the continental and oceanic crusts as well as in the sea itself is simply so vast. If uninhibited extraction were to continue, however, a situation might be reached, which could be termed "effective" exhaustion, where the cost of producing a further ton in terms of energy, water and environmental damage will be so great, that mining activities would automatically cease. Our society, or world economy, would switch to a cheaper, more readily available, but for the purpose, less appropriate substitute. In the very long-term, this non-sustainable process of "unlimited substitution" could in principle go on indefinitely, but with disastrous consequences for future generations.

We can only hope that at some point world population and consumption per capita will cease to grow, in which situation the demand for raw materials will remain constant, corresponding to a maximum in the level of in-use stock. Under such conditions, improved recycling could in principle then supply the majority of global materials needs. However, although elements are never destroyed (except in the case of nuclear reactions) and thus remain potentially available, recycling can never be $100 \%$ efficient. Due to the loss of material at very high dilution in the environment (dispersion) and in the recycling processes themselves, fresh ore will always be necessary. For this reason, effective exhaustion is probably inevitable, but the timescale on which this will happen is long term and ill-defined.

\section{REFERENCES}

[1] Vidal O., Goffe B. and Arndt N., Nat. Geosci., 6 (2013) 894.

[2] Hertwich E. G., Gibon T., Bouman E. A., Arvesen A., Suh S., Heath G. A., Bergesen J. D., Ramirez A., Vega M. I. and Shi L., Proc. Natl. Acad. Sci. U.S.A. (2014) DOI: 10.1073/pnas.1312753111.

[3] United States Geological Survey (USGS), Data Series 140, Historical statistics for mineral and material commodities in the Unites States (2014 Version). minerals.usgs.gov/ minerals/pubs/historical-statistics/.

[4] Report: The world at six billion (United Nations (UN)) 1999. 


\section{EPJ Web of Conferences}

[5] Report: World population prospects: The 2012 revision, United Nations (UN), 2013.

[6] Maddison A., Historical Statistics of the World Economy: 1-2008 AD, ggdc.net/ maddison/Historical_Statistics/vertical-file_02-2010.xls.

[7] Report: Energy critical elements: Securing materials for emerging technologies, American Physical Society and Materials Research Society, 2011.

[8] Moss R. L., Tzimas E. Kara H., Willis P. and Koorosh J., Report: Critical metals in strategic energy technologies (European Commission: Joint Research Centre, Petten, Netherlands) 2011.

[9] Achzet A., Reller A., Zepf V., Rennie C., Ashfield M. and Simmons J., Report: Materials critical to the energy industry. An introduction (University of Augsburg, Germany) 2012. Second edition 2014.

[10] Report: Securing the supply chain for wind and solar energy (RE-SUPPLY) (E4Tech, London/Lausanne and Avalon Consulting, Mumbai, India) 2012.

[11] Report: Minerals, critical minerals, and the US economy (National Research Council of the National Academies, Washington DC) 2008.

[12] Graedel T. E., Barr R., Chandler C., Chase T., Choi J., Christoffersen L., Friedlander E., Henly C., Jun C., Nassar N. T., Schechner D., Warren S., YAng M. and Zhu C., Environ. Sci. Technol., 46 (2012) 1063.

[13] Achzet B. and Helbig C., Resources Policy, 38 (2013) 435.

[14] Chen C. H., The prices of rare earth metals Dy and Nd have lowered $86 \%$ and $78 \%$ respectively from their 2011 peaks (Magnet Energy Corp) magnetnrg.com/news1.

[15] Oxford English Dictionary (OUP, Oxford) 2012.

[16] Report: Critical raw materials for the EU, European Commission (Directorate-General Enterprise and Industry, Brussels) 2010 Revised version, 2014.

[17] Bradshaw A. M., Reuter B. and Hamacher T., Green, 3 (2013) 93.

[18] Bradshaw A. M., Hamacher T. and Fischer U., Fusion Engin. Des., 86 (2011) 2770.

[19] Bradshaw A. M. and Hamacher T., Fusion Engin. Des., 88 (2013) 2694.

[20] Sagawa M., Fujimura S., Togawa N., Yammoto H. and Matsura Y., J. Appl. Phys., 55 (1984) 2083.

[21] Cront J. J. and Herbst J. F., MRS Bull., 13 (1988) 37.

[22] НАтсн G., Lecture: A brief overview of recent rare earth supply and pricing dynamics (Technology Metals Research (TMR)) 2012. almainternational.org.

[23] Hughes A., Electric motors and drives: Fundamentals, types and applications, 3rd edition (Elsevier/Newnes, Oxford) 2006.

[24] Hau E., Wind turbines (Springer, Berlin) 2006.

[25] Report: Technology Roadmap Wind Energy (International Energy Agency, Paris) 2014.

[26] Report: Windenergie Report Deutschland 2013 (Fraunhofer-Institut für Windenergie und Energiesystemtechnik (IWES), Kassel, Germany) 2014.

[27] Mineral Commodity Summaries 1997 - 2014 (United States Geological Survey (USGS) Reston, VA) 2013. minerals.usgs.gov.

[28] Craig J. R., Vaughan D. J. and Skinner B. J., Earth Resources and the Environment, 4th edition (Prentice Hall, Boston) 2011.

[29] Report: Key World Energy Statistics 2013 (International Energy Agency, Paris) 2014.

[30] Report: Lanthanide resources and alternatives (Oakdene-Hollins, London, UK) 2010.

[31] Alonso E., Sherman A. M., Wallington T. J., Everson M. P., Field F. R., Roth R. and Kirchain R. E., Environ. Sci. Technol., 46 (2012) 3406.

[32] Photovoltaics Report (Fraunhofer Institute for Solar Energy Systems ISE, Freiburg, Germany) 2013

ise.fraunhofer.de/de/downloads/pdf-files/aktuelles/photovoltaics-report-inenglischer-sprache.pdf. 


\section{LNES 2014}

[33] First Solar, Press release 19. 03. 2014: First Solar sets thin film module efficiency of 17.0 percent. investor.firstsolar.com/releases.cfm.

[34] TSMC, TSMC solar CIGS Technology. tsmc-solar.com/technology/cigs-technology.

[35] Bleiwas D. I., Report: By-product mineral commodities used for the production of photovoltaic cells, USGS Circular No. 1365 (USGS, Reston, Virginia) 2010. minerals. usgs.gov.

[36] George M. W., Report: Selenium and tellurium, Minerals Year Book (USGS) 2011. minerals.usgs.gov.

[37] Goonan T. G., Report: Materials flow of indium in the United States in 2008 and 2009, USGS Circular 1377 (USGS) 2012. minerals.usgs.gov.

[38] Tolcin A. C., Report: Cadmium, Minerals Year Book (USGS) 2011; Indium, ibid 2011. minerals.usgs.gov.

[39] Jaskula B. W., Report: Gallium, Minerals Year Book (USGS) 2011. minerals.usgs.gov.

[40] US Department of Energy (DOE): Website: SunShot Initiative, 2013 energy.gov/eere/ sunshot/sunshot-initiative.

[41] Zweibel K., Science, 328 (2010) 699.

[42] Fthenakis V. and Anctil A., IEEE J Photovoltaics, 3 (2013) 1.

[43] Tahill W., Report: How much lithium does a LiIon battery really need? (Meridian International Research, Martainville) 2010. evworld.com/library/lithium_shortage. pdf.

[44] Maisonnier D., Fusion Eng. Des., 83 (2008) 858.

[45] Cook E., Science, 206 (1979) 1141.

[46] Nuttal W. J., Clarke R. H. and Glowacki B. A., Nature, 485 (2012) 573.

[47] Nuttal W. J., Clarke R. H. and Glowacki B. A. (editor), The Future of Helium as a Natural Resource (Routledge, Abingdon and New York) 2012.

[48] Axford W. I., J. Geophys. Res., Space Phys., 73 (1968) 6855.

[49] Garvey M. D., CryoGas International, 49 (2011) 30.

[50] Clarke R. H. and Cai Z., in ref. [41], p. 235.

[51] SERIO L. (ITER), personal communication.

[52] Boccaccini L. and Franza F., (Karlsruhe Institute of Technology), personal communication.

[53] Clarke R. H. and Clare R., in ref. [38], p. 118.

[54] Mitchell N. (ITER), personal communication.

[55] Tilton J. E., On Borrowed Time? Assessing the Threat of Mineral Depletion (Resources for the Future, Washington DC) 2002. 